
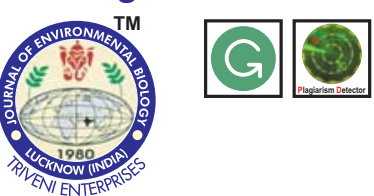

\title{
Antifungal potential of hot spring water of Manikaran, Himachal Pradesh (India)
}

Authors Info

S. Devi" and S. S. Kanwar ${ }^{2}$

${ }^{1}$ Department of Basic Sciences, College of Forestry, Dr. Y.S. Parmar University of Horticulture and Forestry-Nauni, Solan - 173230 , India

${ }^{2}$ Department of Microbiology, College of Basic Sciences, CSK, Himachal Pradesh Agricultural University, Palampur - 176062 , India

*Corresponding Author Email : sunitachamba@gmail.com

Key words

Antifungal activity,

Fungal diversity,

Hot spring,

Phytopathogens,

Thermophilic fungi

Publication Info

Paper received : 12.05 .2015

Revised received: 18.01.2016

Re-revised received : 29.03 .2016

Accepted : 07.06.2016

\section{Abstract}

Aim: Natural geothermal sites are considered as the most favourable locations for the isolation of thermophilic microorganisms. Many researchers have isolated thermophilic fungi from various hot springs located worldwide viz. United States, Argentina, China, Indonesia, Taiwan, India etc. The present study aimed to determine the diversity of culturable thermotolerant and/or thermophilic fungal species in hot spring of Manikaran, Himachal Pradesh (India).

Methodology: Potato dextrose agar (PDA), Sabouraud dextrose agar (SDA) and yeast starch agar media were used to determine the fungal diversity.

Results: No fungal growth was detected on PDA, SDA and yeast starch agar media after repeated examinations. Therefore, an attempt was made to check antifungal activity of water on some known fungal plant pathogens viz. Sclerotium rolfsii, Fusarium oxysporum, Sclerotinia sclerotiorum and Pythium aphanidermatum. A strong inhibition in the growth of these pathogens was observed on potato dextrose agar medium prepared with Manikaran hot spring water.

Interpretation: This inhibition might be mediated through some volatile compounds as evident from the results of antagonistic assay used for the detection of volatile antifungal compounds as shown below in the figure. This is the first report on Manikaran hot spring water where antifungal activity was observed, though earlier workers have reported the presence of thermotolerant fungi in this water.
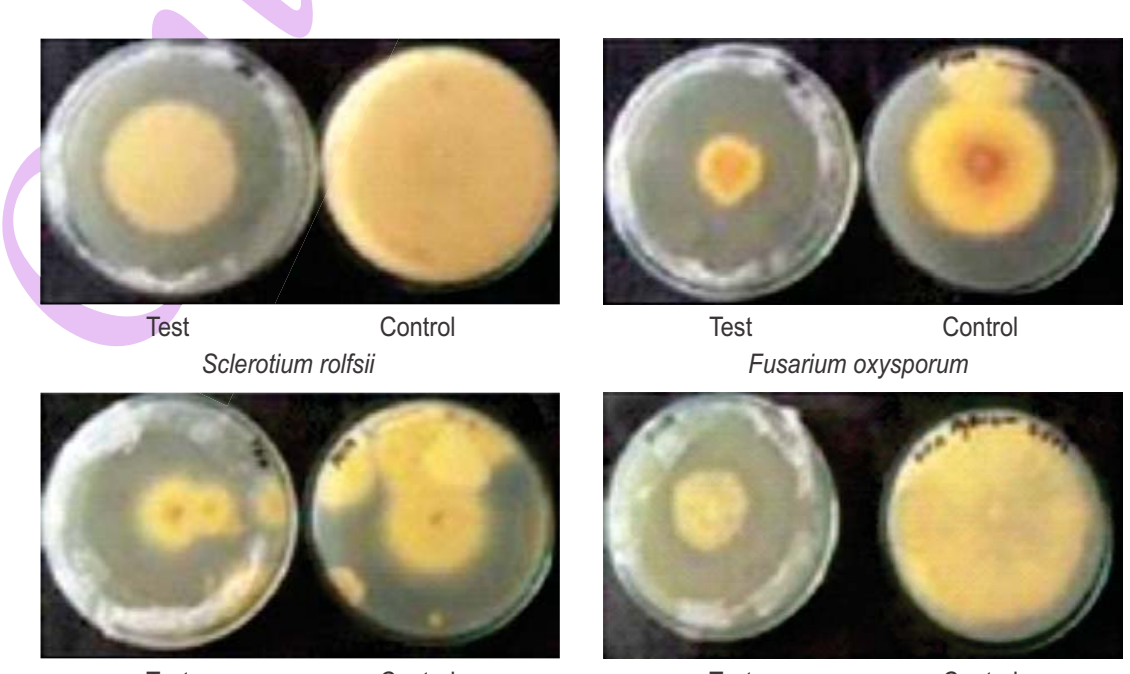

Test

Control

Sclerotinia sclerotiorum

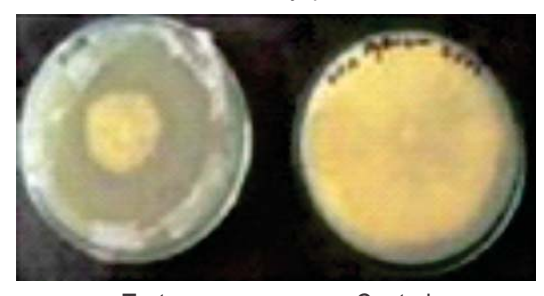

Control

Pythium aphanidermatum 


\section{Introduction}

Geothermal springs in India, located in different geological environments, are broadly distributed into seven provinces: Himalaya, Sohana, Cambay, West Coast, Son-Narmada-Tapi (SONATA), Godavari and Mahanadi (Chandrasekharam, 2000). Hot springs are the emerged water bodies produced by geo-thermally heated groundwater from the earth's crust (Kazue et al., 2006). The temperature of water in hot springs lies significantly above the mean temperature of that region (Sen et al., 2010). High temperature of water and/or soil exerts pressure on microbial species leading to the selection of specific flora capable of tolerating and surviving heat stress.

Hot springs areas are attractive places for locals and foreigners either for excursion or for medical purposes such as for healing of various types of diseases. This is because the hot spring water is believed to be rich in salt, sulfur and sulfate in water body. For several years, people have used hot springs water both for cozy bathing and therapy (Hamzah et al., 2013). Presence of various elements and ions, especially sulphur (S) and sulphate ion $\left(\mathrm{SO}_{4}{ }^{2}\right)$ make hot spring water suitable for medical purposes especially for skin therapy. Sulphur is a chemical element with strong antifungal potential, present abundantly in hot spring water

Nature has blessed the state of Himachal Pradesh state with a number of hot springs viz Vashisht, Manikaran, Kasol, Tattapani, Khirganga etc. Some of these hot springs are probably rich repository of thermophilic organisms and Manikaran is one of such hot springs which has always remained as attractive site for exploring its diversity by various researchers (Devi and Kanwar, 2016). The water of this hot spring has strong smell of sulphur suggesting the presence of sulphur element either as free or in combined form. In view of these facts, a study on Manikaran hot spring water was performed with the objectives of elucidadating its fungal diversity and to determine the antifungal potential of hot spring water against some phytopathogens

\section{Materials and Methods}

Sampling : Three different sites: upper Manikaran, lower Manikaran and Shangna were selected for collection of microbial samples. Three types of samples (water, soil and biomat) in five replicates (total 45 samples) were collected in sterile falcon tubes from these selected sites and brought to laboratory for analysis under aseptic conditions.

Sample analysis : Temperature and $\mathrm{pH}$ of the samples were recorded at the time of sample collection with the help of portable temperature probe (Fisher Scientific, Mumbai, India) and $\mathrm{pH}$ meter (CyberScan, Singapore), respectively. Five measurements were done and mean value was calculated for each sample

Fungal isolation : To isolate fungi from hot spring samples, four techniques: traditional Standard plate count technique (Wollum,
1982), Membrane filter technique (Mulvany, 1969), on-site culturing (Akmar et al., 2011) and Enrichment technique (Holt and Krieg, 1994) were employed in this study.

In traditional standard plate count technique, directed pour plate and serial dilutions methods were performed. In direct pour plate method, $5 \mathrm{ml}$ of sample was mixed with $15 \mathrm{ml}$ sterilized and melted PDA (Hi-media), SDA (Hi-media) and yeast starch agar media (Hi-media) separately. In serial dilution method, samples were serially diluted to 10 folds by distilled water and 0.1 $\mathrm{ml}$ of each diluted sample was spread on PDA(Hi- media), SDA(Hi-media) and yeast starch agar media (Hi-media) separately with three replicates every time. Plates were incubated at different temperatures i.e., 20,37 and $55^{\circ} \mathrm{C}$ for $3-5$ days.

Besides traditional methods, alternative membrane filter technique was also applied to concentrate fungi in a large volume of sample. One hundred milliliter of each sample was filtered

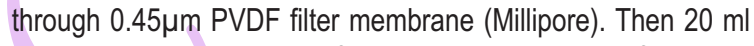
distilled water was used to flush this membrane and finally the membrane was placed on PDA plates which were then incubated at different temperatures i.e., 20,37 and $55^{\circ} \mathrm{C}$ for $3-5$ days.

In addition to this, on-site culturing technique was also done where direct plating of the samples was done immediately after collecting the samples. Plates were then placed in a vaccine carrier in order to maintain the incubation temperature.

Generally, thermophilic fungi occur relatively in low numbers in natural habitats, therefore, enrichment is required prior to isolation. For this, $10 \mathrm{ml}$ or $10 \mathrm{~g}$ of samples were transferred into $100 \mathrm{ml}$ of broth media (Potato dextrose broth, Sabouraud dextrose broth and yeast starch broth) and incubated at 20,37 and $55^{\circ} \mathrm{C}$ for $3-5$ days. The samples were then serially diluted and plated on PDA (Hi-media), SDA (Hi-media) and yeast starch agar media (Hi-media) separately with three replicates every time. Plates were incubated at temperature and time as referred above.

Detection of volatile compounds nature of antifungal compounds : The volatile nature of antifungal compounds was detected by the method of Fernando and Linderman, (1994) with slight modifications. Hot spring water was placed on the lid of the inverted petriplate (except for control plates) containing PDA medium (prepared with distilled water) and $5 \mathrm{~mm}$ mycelial plugs of fungal pathogens were placed on potato dextrose agar. These plates were then immediately wrapped in parafilm to seal-in the volatiles and incubated at $28^{\circ} \mathrm{C} \pm 2^{\circ} \mathrm{C}$ for $3-7$ days.

\section{Results and Discussion}

The fungal diversity present in all types of samples i.e., water, soil (sediment) and biomat was elucidated by employing four techniques viz., traditional standard plate count technique 


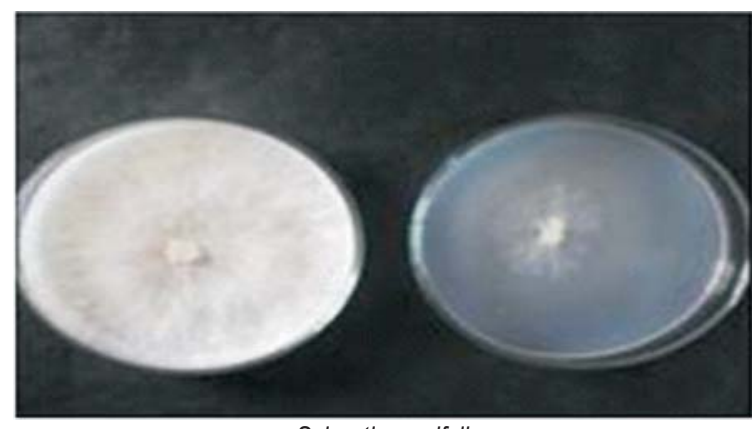

Sclerotium rolfsii

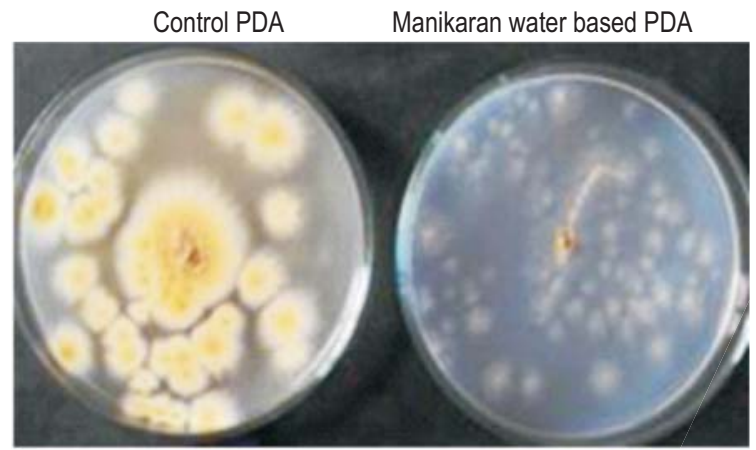

Sclerotinia sclerotiorum

Control PDA

Manikaran water based PDA

Fig. 1 : Effect on the growth of fungal plant pathogens

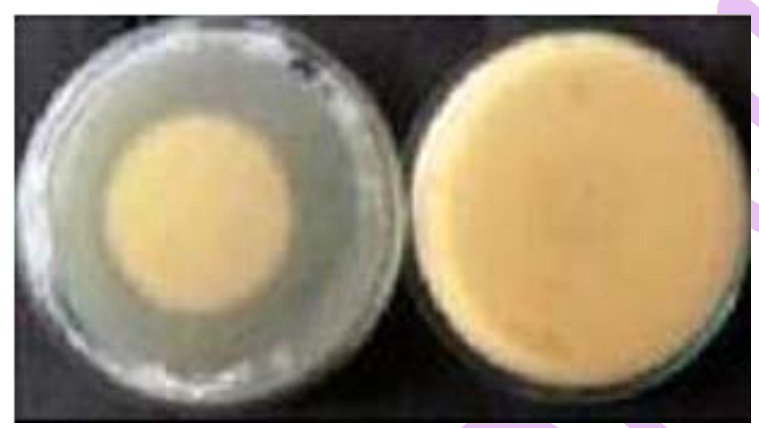

Test

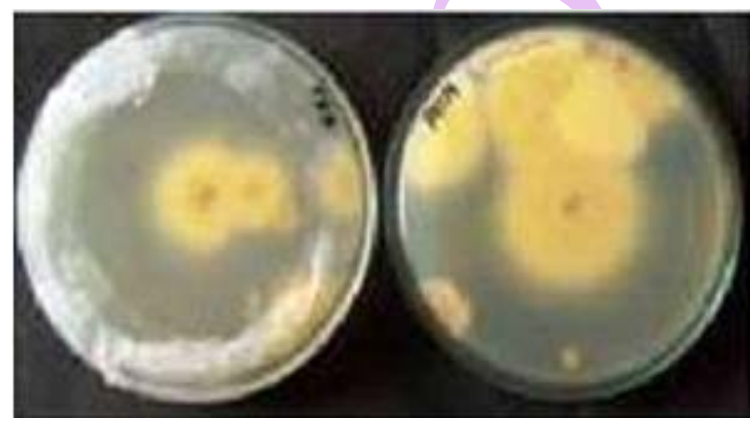

Test Sclerotinia sclerotiorum Control

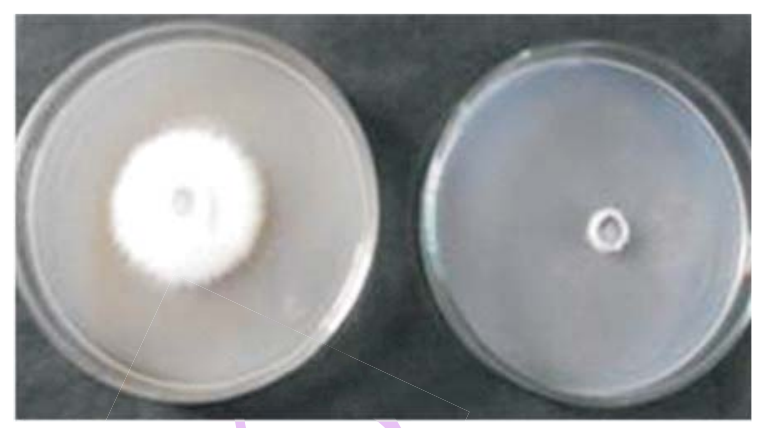

Fusarium oxysporum

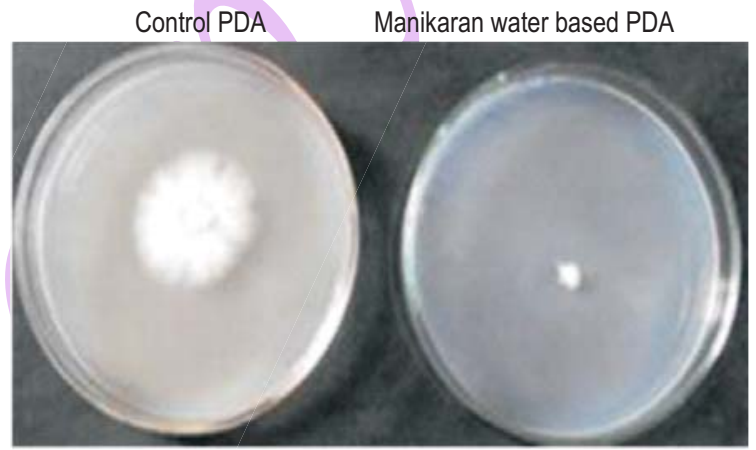

Pythium aphanidermatum

Control PDA Manikaran water based PDA

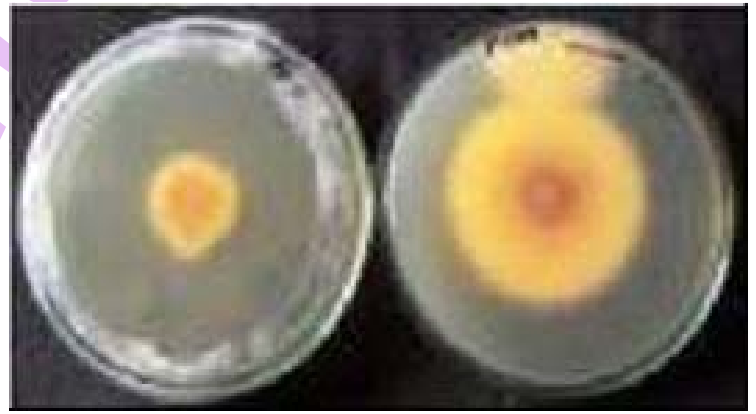

Test Fusarium oxysporum Control

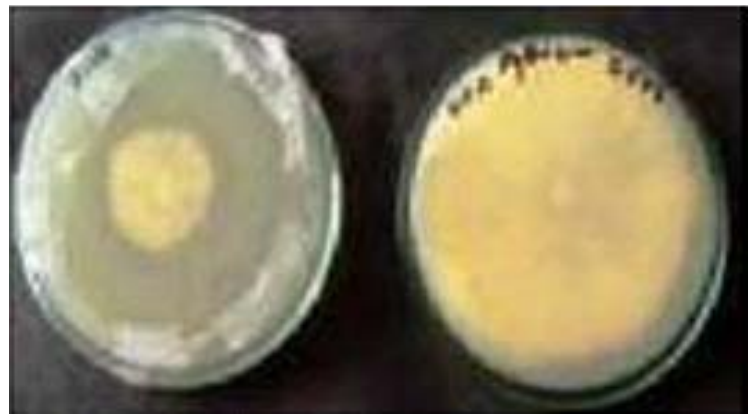

Test Pythium aphanidermatum Control

Fig. 2 : Plates showing the presence of volatile antifungal compounds in hot spring water of Manikaran; (Test means volatile antifungal compounds have inhibited the growth of phytopathogen); (Control means phytopathogen was not treated with volatile antifungal compounds present in hot spring water) 
i.e., pour plate and spread method, membrane filter technique, on-site culturing and enrichment technique in this study. However, in the present study, no fungal growth was observed in all the three types of samples collected from Manikaran hot spring by traditional methods. Therefore, alternative methods like membrane filter technique that can concentrate the sample, onsite culturing where direct plating of the samples was done and finally the enrichment technique where the growth of unwanted species got suppressed, were attempted. But, no fungal growth was observed from all types of samples by using all these techniques. However, Verma et al., (2012) reported some thermotolerant fungal isolates viz. Penicillium citrinum, Paecilomyces variotii, Pichia guilliermondii, Paecilomyces sp. and Aspergillus sydowiffrom Manikaran hot spring water and soil samples. Likewise, Sharma et al., (2013) reported the presence of fungus Myceliophthora thermophila SH1 in the Manikaran hot spring water samples. Although some species of fungi have been reported from various adverse environments such as hot springs (Maheshwari et al., 2000) or geothermal soils (Redman et al., 1999) but, thermophily in fungi is a rare phenomenon and about 50 species, out of 100,000 recorded fungal species, have the ability to successfully grow at elevated temperatures (Salar and Aneja, 2007) thereby indicating that all these 50 species were absent in the Manikaran hot spring. Whereas, thermophily is a common phenomenon in eubacteria and archaea ( Blöchl et al., 1997; Rainey and Oren, 2006). Generally, the temperature limit for thermophilic fungi is $60-62^{\circ} \mathrm{C}$, however, a thermophilic fungal isolate Thermomyces lanuginosus isolated from the hot springs of Taiwan (site temperature $80^{\circ} \mathrm{C}$ ), could grow even at $64^{\circ} \mathrm{C}$ which represents the highest upper growth temperature of all the fungi so far recognized (Tansey and Brock, 1972).

To cross check these findings, two types of experimental approaches were adopted. In the first experimental approach, two types of potato dextrose agar were prepared i.e., one with distilled water (serve as control) and other with Manikaran hot spring water. Both the media were autoclaved and poured into petriplate. The petriplates were inoculated with $5 \mathrm{~mm}$ mycelia plugs of known mesophilic fungal plant pathogens viz. Sclerotium rolfsii, Fusarium oxysporum, Sclerotinia sclerotiorum and Pythium aphanidermatum and incubated at $28^{\circ} \mathrm{C} \pm 2^{\circ} \mathrm{C}$ for $3-7$ days. A strong inhibition (Fig. 1) was observed in the growth of these fungal pathogens in Manikaran water based PDA as compared to control PDA(Hi-media).

On the basis of these results, it is evident that some antifungal compounds might be present in hot spring water of Manikaran which are restricting/inhibiting the growth of these tested fungal pathogens. No doubt, the recorded temperature of water was quite high in the spring under study and volatile compounds might escape at high temperature but on searching the literature, many references were found where presence of volatile substances has been reported even at $400^{\circ} \mathrm{C}$ or above i.e. in hydrothermal vents (Konn et al., 2012). To find out whether these compounds are volatile or non-volatile, subsequent experiment was conducted by the method of Fernando and Linderman, (1994) with slight modifications. Inhibition in fungal growth (Fig. 2) in different plates was observed indicating the presence of some volatile antifungal compounds in the water, as there was no direct interaction of water with the pathogens.

Thus, it can be concluded from the present study that antifungal activity exists in Manikaran hot spring water where volatile antifungal compounds might be playing some role in its exhibition.

\section{Acknowledgment}

The author, Mrs. Sunita Devi, is thankful to the University Grants Commission for awarding Rajiv Gandhi National Fellowship to carry out this work.

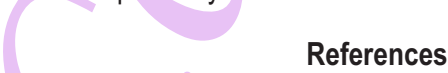

Akmar, H.N., I. Asma, B. Venugopal, L.Y. Latha and S. Sasidharan: Identification of appropriate sample ane culture method for isolation of new thermophillic bacteria from hot spring. Afr. J. Microbiol. Res., 5, 217-221 (2011).

Blöchl, E., R. Rachel, S. Burggraf, D. Hafenbradl, H.W. Jannasch and K.O. Stetter: Pyrolobus fumarii, gen. and sp. nov., represents a novel group of archea, extending the upper temperature limit for life to $113^{\circ} \mathrm{C}$. Extremophiles, 1, 14-21(1997).

Chandrasekharam, D.: Geothermal energy resources of india: Country update. Proceedings World Geothermal Congress, Japan, pp. 133-145 (2000).

Devi, S. and S.S. Kanwar : Deciphering the diversity of aerobic culturable thermophiles in hot springs of Manikaran, Himachal Pradesh. Int. J. Farm. Sci., 6, 156-162 (2016).

Fernando, W.G.D. and R. Linderman: Inhibition of Phytophthoravignae and root rot of cowpea by soil bacteria. Biol. Agric. Hortic., 12, 1-14 (1994).

Holt, J.G. and N.R. Krieg: Enrichment and Isolation. In: Methods for General and Molecular Bacteriology (Ed: P. Gerhardt). ASM Publication, pp. 197-200 (1994).

Hamzah, Z., N.L. Abd Rani.,A. Saat and A.K. Wood: Determination of hot springs physico-chemical water quality potentially use for balneotherapy. Malays. J. Ana. Sci., 17, 436 - 444(2013)

Kazue, T., M. Okuno, M. Furumoto and H. Watanabe: Biomineralization of pisoliths in hot springs. Mater. Sci. Eng., 26, 617-623 (2006).

Konn, C., J.L. Charlou, J.P. Donval and N.G. Holm: Characterisation of dissolved organic compounds in hydrothermal fluids by stir bar sorptive extraction - gas chomatography-mass spectrometry. Case study: the Rainbow field ( $36^{\circ} \mathrm{N}$, Mid-AtlanticRidge). Geochem. Trans. , 13, 1-19 (2012).

Maheshwari, R., B. Girish and K.B. Mahalingeshwara: Thermophilic fungi: Their physiology and enzymes. Microbiol. Mol. Biol . Rev., $64,461-488(2000)$.

Mulvany, J.G.: Membrane filter technique in Microbiology. Method. Microbiol., 1, 205-253(1969).

Redman, R.S., A. Litvintseva, K.B. Sheehan, J.M. Henson and R.J. Rodriguez: Fungi from geothermal soils in Yellowstone National 
Park. Appl. Environ. Microbiol., 65, 5193-5197(1999).

Rainey, F.A. and O. Aharon: Extremophile microorganisms and the methods to handle them. Method. Microbiol., 35, 1-25 (2006).

Salar, R.K. and K.R. Aneja: Thermophilic Fungi: Taxonomy and Biogeography. J. Agr. Technol., 3, 77-107 (2007).

Sen, S.K., S.K. Mohapatra, S. Soumya and G.T.V. Rao: Characterization of hot water spring source isolated clones of bacteria and their industrial applicability. Int. J. Chem. Res., 2, 01-07 (2010).

Sharma, N., G. Vyas and S. Pathania: Culturable diversity of thermophilic microorganisms found in hot springs of Northern Himalayas and to explore their potential for production of industrially important enzymes. Sch.Acad. J. Biosci., 1, 165-178(2013).

Tansey, M.R. and T.D. Brock: The upper temperature limit for eukaryotic organisms. Proc. Natl. Acad. Sci. USA., 69, 2426-2428 (1972).

Verma, P., A.N. Yadav, A. Suman and A.K. Saxena: Isolation and molecular characterization of thermotolerant lignocellulose producing fungi from manikaran thermal springs. Natl. Symp. Microbes. Health. Agric., p. 82 (2012). (DOI: 10.13140/RG.2.1. 2656. 9126).

Wollum, A.G.: Cultural methods for soil microorganisms. In: Methods of soil analysis, Part II, chemical and microbiological properties. American Society of Agronomy, Inc. Publisher Madison, Wisconsin, USA, pp. 781-802 (1982).

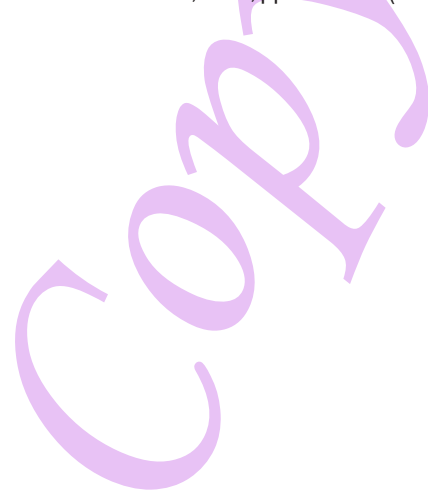

